\title{
Comparison of global geomagnetic field models and evaluation using marine datasets in the north-eastern Atlantic Ocean and western Mediterranean Sea
}

\author{
Jean-François Oehler ${ }^{*} \mathbb{0}$, Didier Rouxel and Marie-Françoise Lequentrec-Lalancette
}

\begin{abstract}
Many models describing the Earth's magnetic field exist and are maintained by international research organizations. However, no clear general overview of the cross-compared quality of these models is available. An evaluation of the internal component and of the anomaly field as estimated by a selection of nine geomagnetic models with global coverage is presented here. Anomaly field models are also compared with an external, independently processed marine dataset extracted from Shom's (the French Hydrographic and Oceanographic Service) geophysical database. The comparative study shows that internal geomagnetic fields computed outside the provisional domain, up to degrees 12 or 13 of spherical harmonics (SH), can be considered as equivalent. Relative amplitude differences with the World Magnetic Model 2015 (WMM2015) and the 12th generation of the International Geomagnetic Reference Field (IGRF-12) taken as references are lower than 10 nT. For an extent reduced to the north-eastern Atlantic Ocean and western Mediterranean Sea, anomaly field models up to SH degree 720 and the 3rd version of the Earth Magnetic Anomaly Grid (EMAG2v3) at the equivalent $0.5^{\circ}$ resolution are the closest models to the filtered marine data. However, they are significant spatial discrepancies and standard deviations of differences between models and data are about 65 nT. The 3-arc-minute World Digital Magnetic Anomaly Map (WDMAM) best reflects the unfiltered marine data, but with significant standard deviations of about $70 \mathrm{nT}$. Results demonstrate that any model can be used with insignificant errors to compute raw anomalies from total field measurements by removing the internal component of the Earth's magnetic field. In addition, they suggest that the priority should be given to WDMAM for levelling and evaluating marine datasets and for computing enhanced high-resolution regional magnetic maps.
\end{abstract}

Keywords: Geomagnetic field models, Spherical harmonics, Internal component, Anomaly field, Marine data, Comparative analysis

\section{Introduction}

Global geomagnetic models mathematically describe the Earth's magnetic field (see Langel 1987; Backus et al. 1996). The geomagnetic field is the sum of three contributions: (1) the main (or internal) field originating from the Earth's core (dynamo effect), which is variable in time (secular variations) and represents about $95 \%$ of the total field at the surface; (2) the anomaly field from crustal,

\footnotetext{
*Correspondence: jean-francois.oehler@shom.fr Shom (French Hydrographic and Oceanographic Service), 13 rue du Chatellier, CS 92803, 29228 Brest Cedex 2, France
}

mantle or anthropic sources; and (3) the external field from the upper atmosphere and magnetosphere, which is highly dependent on solar activity.

Many geomagnetic models exist and are being developed, maintained and updated by several research organizations all over the world and have been published in scientific literature. The scope of applications is very broad, ranging from fundamental research to geophysical surveying and object detection. At Shom (the French Hydrographic and Oceanographic Service), only internal and anomaly field models are currently used. The internal World Magnetic Model (WMM, see references 
in Table 1) is used for applications in sea and air navigation, as required by NATO's standards (Defense Mapping Agency 1993). The International Geomagnetic Reference Field (IGRF, Table 1) is the reference model adopted by the scientific community to correct the main field and derive magnetic anomalies. Global anomaly field models, such as the Earth Magnetic Anomaly Grid (EMAG) or the World Digital Magnetic Anomaly Map (WDMAM) (Table 1), are used to level and evaluate marine datasets. They can also be used for computing enhanced regional magnetic maps.

Whether models are sometimes assessed through intrinsic comparisons with data used to produce them or extrinsically against concurrent models before dissemination to the scientific community, the only study dealing with the comparison of a wide range of recent versions of geomagnetic models relates to the evaluation of candidate models for the production of the reference model IGRF-12 from IAGA (Thébault et al. 2015a, b). IGRF-12 commonly corresponds to a weighted average of several internal models expressed in spherical harmonics $(\mathrm{SH})$ to degree 13 and provided by a number of different international research laboratories and institutions. Thébault et al. (2015b) observe deviations between the ten candidate models. However the root mean square vector difference field between models as defined by the authors are generally less than $10 \mathrm{nT}$. They conclude that the internal models submitted are relatively homogeneous. The present paper gives additional results to the evaluation performed for IGRF-12. Its aim is to present an evaluation from the selection of nine magnetic models with global coverage that are compared for the same spectral content, and with an external, independently processed marine dataset. The selected models characterize not only the internal component of the Earth's magnetic field up to SH degree 14 (IGRF-12, WMM2015 and COVOBS.x1) but also, the combination of the internal component and the anomaly field with $\mathrm{SH}$ degrees up to 65 and 720 (CM4, POMME-9, EMM2015 and HDGM2016), and only the anomaly field through high-resolution grids (EMAG2v3 and WDMAM; see references in Table 1). External contributions to the Earth's magnetic field are not considered here.

The selected models are freely available in digital form. They describe at least the intensity of the total magnetic field and span the period 2010-2015. Exceptions are made for CM4 which is estimated only before July 2002, for WMM2015 which is considered to be valid only between 2015 and 2020, and for the licensed HDGM2016 which has been purchased by Shom for their own studies.

Most models (WMM2015, EMM2015, HDGM2016, POMME-9, see references in Table 1) are calculated using a serial approach (Thébault et al. 2010). It consists of a computation of Gauss coefficients by inversion to independently estimate the internal and anomaly components of the magnetic field on one hand, and (when appropriate) the external component on the other hand. Components are then aggregated to obtain the final model. The CM4 model results from a comprehensive approach (Sabaka et al. 2004, 2015) where all components are directly co-estimated. COV-OBS. $\mathrm{x} 1$ is an original model, as it is the only one estimated using a stochastic method (Gillet et al. 2013, 2015). Models are mainly built from recent satellite data from

Table 1 Main characteristics of the evaluated global geomagnetic field models

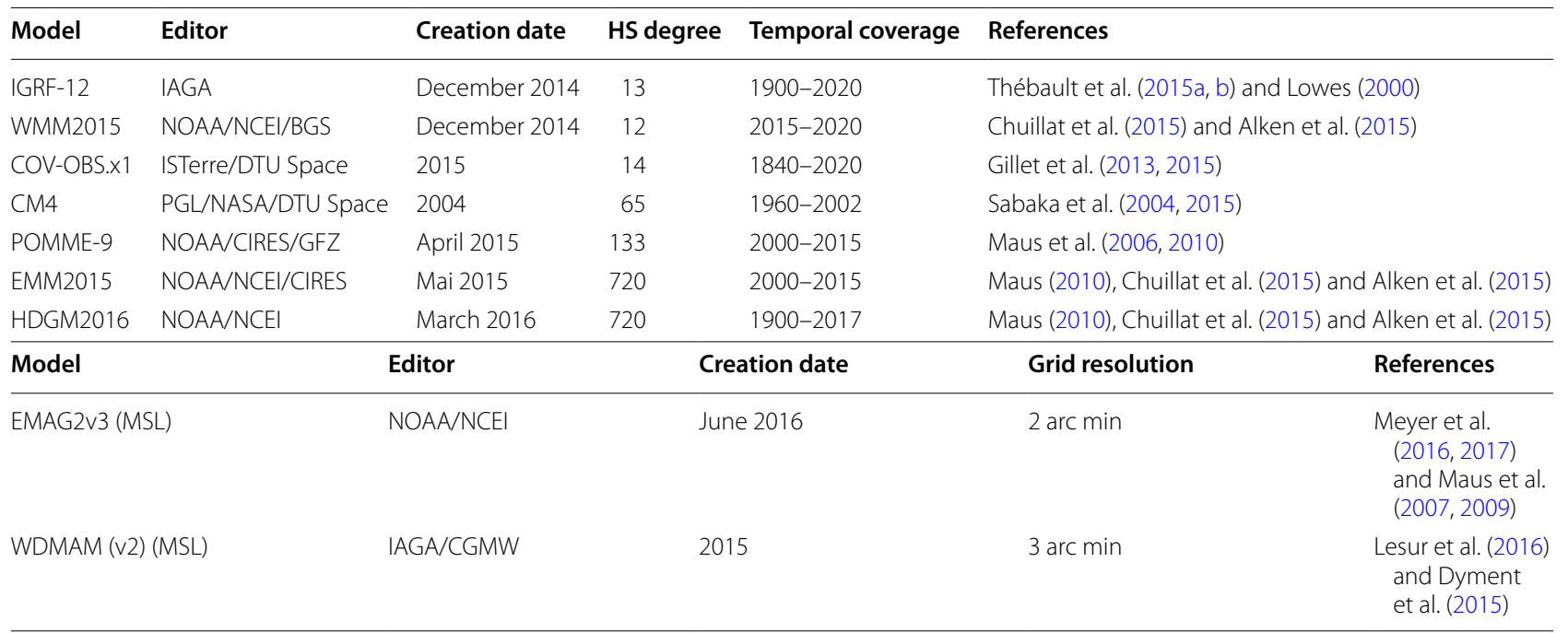


SWARM (ESA), OERSTED (DTU Space), CHAMP (GFZ) and SAC-C (NASA) programs and monthly or annual averages from magnetic observatories. Highresolution models with an anomaly component (i.e. EMM2015 and HDGM2016) are based on EMAG2 version 2 anomaly grid (Maus et al. 2009) and therefore indirectly include marine, land-based and airborne measurements. EMAG2 version 3 (EMAG2v3) and WDMAM version 2 (see references in Table 1 ) are very high-resolution anomaly grids (with grid spacings of 2 and 3 arc minutes, respectively) calculated at the mean sea level. The short-wavelength field is computed from processed and levelled marine, land-based and airborne measurements, and precompiled anomaly grids. The long-wavelength field is corrected by substituting the longest wavelengths (greater than about $300 \mathrm{~km}$ ) with models derived from satellite data (MF7 for EMAG2v3 and GRIMM L120 for WDMAM). EMAG2v3 is calculated from observed data using a kriging process without a priori geologic structure and ocean-age information. WDMAM results from overlap management by attributing an order of precedence for each dataset and weighted averaging in conflicting areas. A forward model of marine magnetic anomalies, built from an age map of the ocean floor, relative plate motions and a geomagnetic polarity time scale, is used to fill data gaps and compute the model over all oceanic areas.

The main purpose of the present work is to evaluate the internal component and anomaly field as estimated by the selected models (Fig. 1), with particular concern on the discrepancies between them, and ultimately to identify the best candidates adapted for Shom's applications. The anomaly field is also evaluated with processed data extracted from Shom's marine magnetic database, which are an independent source of measurements. Results are shared with the scientific community as they are an overview of the cross-compared quality of geomagnetic models with ground-truthing data.

\section{Methods, models and data processing Evaluation method}

Several comparative scenarios are developed to study the differences between $\mathrm{SH}$ models. We chose to independently consider: (1) the intensity, inclination and declination (when available) of the total field for the internal component, up to $\mathrm{SH}$ degrees 12 and 13, and (2) the intensity of the anomaly field, up to SH degree 720 (Fig. 1). Two geospatial extents are considered: (1) a global scale (land and ocean areas), at $1^{\circ}$ grid spacing and (2) an area of interest covering the north-eastern Atlantic Ocean and the western Mediterranean Sea (hereafter referred to as the NEAWM area with an extent of $\mathrm{N} 20^{\circ}-\mathrm{N} 70^{\circ}$; W $\left.50^{\circ}-\mathrm{E} 20^{\circ}\right)$ at $0.5^{\circ}$ grid spacing. Three dates $(01 / 01 / 2000$ for CM4 only, 01/01/2010 except for WMM2015 and 01/01/2015) are also selected.

The three global HDGM2016, EMAG2v3 and WDMAM anomaly models are evaluated by comparing them with marine data for the NEAWM area only (mainly for computational reasons) at $0.5^{\circ}$ and at full grid spacing for EMAG2v3 and WDMAM. Therefore, either wavelengths lower than $55 \mathrm{~km}$ (equivalent to $\mathrm{SH}$ deg. 720) or the full spectral content of the data and models are considered for the comparison (Fig. 1).

Difference grids and differences between models and measurements are spatially and statistically analysed. Energy spectrums are computed and compared for each model.

\section{Model calculations}

Grids, respectively, showing intensity of the total magnetic field, inclination and declination (when available), are estimated at mean sea level, directly from Gauss

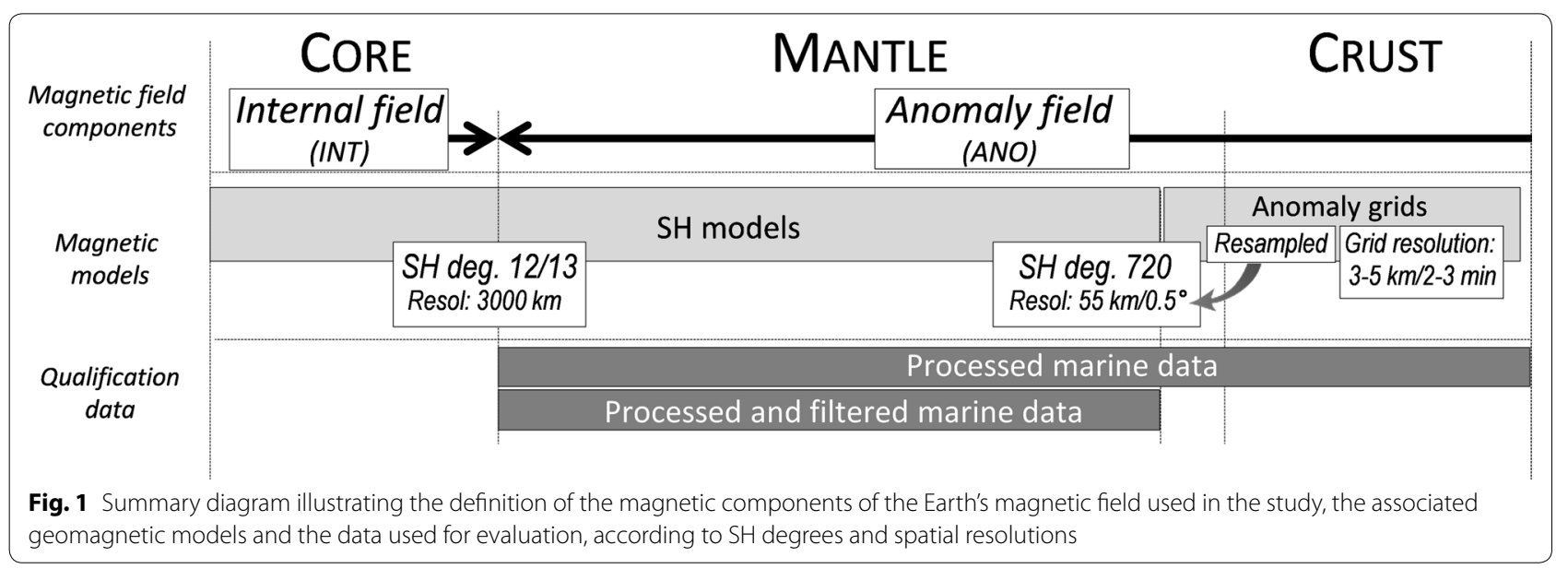


coefficients integrated into Shom's processing tools for IGRF-12, WMM2015 and HDGM2016 models (and also the HDGM2016 core sub-model estimated considering only coefficients up to $\mathrm{SH}$ degrees 13 ) or by using computation programs published and associated with EMM2015, COV-OBS.x1, CM4 and POMME-9 models. Scripts were developed to iteratively execute programs that allow point estimation and thus to compute values on $1^{\circ}$ and $0.5^{\circ}$ grids. EMAG2v3 and WDMAM anomaly grids were also computed by resampling full-resolution published datasets for the targeted $0.5^{\circ}$ grid spacing (Fig. 1).

For all models except WMM2015, the computed grids are filtered using the Oasis montaj software-MAGMAP extension $\left({ }^{\circ} \mathrm{Geosoft}\right)$ to estimate grids describing the internal component of the models only with $\mathrm{SH}$ degrees lower than 12 or 13 (Fig. 1). Tests show that the differences between filtered field intensity grids and the WMM2015 or IGRF-12 estimated grids taken as a reference are minimized using the following parameters, which are generalized in our study: (1) removing/ restoring the average tendency, (2) padding/unpadding using the maximum entropy method (Burg 1975), and (3) applying an order-12 Butterworth filter and a cut-off wavelength equivalent to the next higher $\mathrm{SH}$ degree (i.e. about $3080 \mathrm{~km}$ for $\mathrm{SH}$ degree 12 and $2860 \mathrm{~km}$ for SH degree 13). Statistics are then computed with a global extent reduced by $30^{\circ}$ in latitude and $20^{\circ}$ in longitude to avoid edge-filtering artefacts. Similarly, the NEAWM $0.5^{\circ}$ grids are calculated at a global scale before filtering then reduced to the targeted extent.

Finally, anomaly grids are calculated conventionally by IGRF removal. By definition, only the main internal component of the Earth's magnetic field is consequently removed from anomaly grids. Contributions from mantle and crustal sources are kept in the signal (Fig. 1). IGRF removal is done according to the epoch (i.e. 2010.0 or 2015.0). This can explain why small differences can be observed for the same anomaly field model at two different dates.

\section{Evaluation of the models with marine data}

Marine magnetic data acquired during 71 surveys were extracted from Shom's geophysical database (Fig. 2 and Table 2). About half of them consist of in-house surveys. The others are published by other organizations (i.e. the French National Oceanographic Data Centre (SISMER) and the NOAA National Centers for Environmental Information (NCEI)). Data cover the NEAWM area as patches on the following five geographical sub-areas of interest: (1) mid-Atlantic ridge between $20^{\circ} \mathrm{N}$ and $45^{\circ} \mathrm{N}$, (2) Canary Islands to offshore west Portugal, (3) Bay of Biscay, (4) English Channel to North Sea, and (5) western
Mediterranean Sea. They were chosen to characterize a wide range of geodynamic and geomagnetic contexts, from shallow continental shelves and margins to deep abyssal plains, including the Atlantic mid-oceanic ridge. Data are processed following Shom's methodology (Shom 2007). They are made up of magnetic anomalies corrected only from the IGRF's main theoretical field (IGRF anomaly) and, from low frequency diurnal variations (LF anomalies) or from low frequency diurnal and high frequency agitation variations (LF $+\mathrm{HF}$ anomalies). It should be noted here that the processing technique applied to the data used to build the EMAG2v3 and WDMAM models greatly differs from the one used at Shom. The former uses the CM4 model to correct the total field for internal and external components (see Quesnel et al. 2009; Maus et al. 2009), while the latter uses IGRF reference models and measurements from the nearest permanent magnetic observatory (in distance and in latitude). In Shom's methodology, diurnal variations are thus obtained by (1) filtering the total field measured at the observatory with a low-pass Gaussian filter that only keeps signals with periods of over $5 \mathrm{~h}$, (2) removing the IGRF's main theoretical field at the station and (3) removing a constant local magnetic response estimated by averaging the residual signal over a relatively long period of time (1-6 months). Agitation variations are calculated by subtracting the previous diurnal variations from the total field measured at the observatory.

Shom's datasets were resampled every $200 \mathrm{~m}$ along profiles by a weighted average method. To compare marine data with models defined up to SH degree 720 or subsampled to $0.5^{\circ}$, the highest frequencies $(<55 \mathrm{~km})$ are filtered with an order 8 Butterworth filter after removing the average tendency and padding the data.

\section{Results and discussion Model comparison Intensity of the internal magnetic field}

The intensity of the internal field estimated using global geomagnetic models is evaluated both up to $\mathrm{SH}$ degree 12 with WMM2015 as a reference and SH degree 13 with IGRF-12 as reference (see Additional file 1; Fig. 3). Considering this parameter alone, the WMM2015, EMM2015, HDGM2016(core), POMME-9, CM4 and IGRF-12 models can be considered as equivalent. Mean differences are relatively low, generally smaller than $5 \mathrm{nT}$. Mean standard deviation is less than about $10 \mathrm{nT}$ both on a global scale and for the NEAWM area. For a given resolution, the spatial distribution of the differences is quite similar (see Fig. 3a for the characteristic tendency in SH degree 12 and Fig. 3b, c in SH degree 13). The spectral content of the models is also consistent overall, both at global scale and for the NEAWM 
a

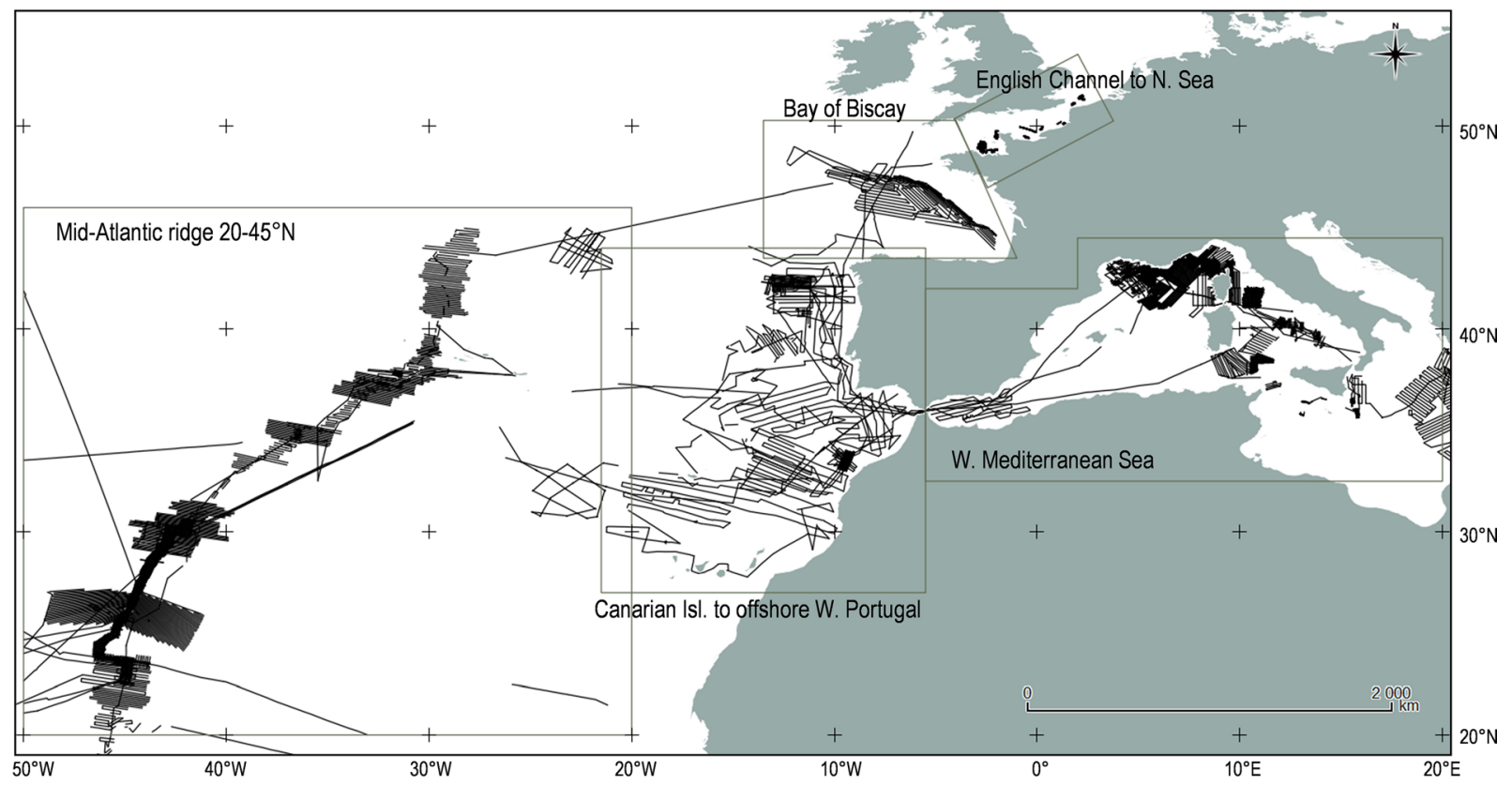

b 25

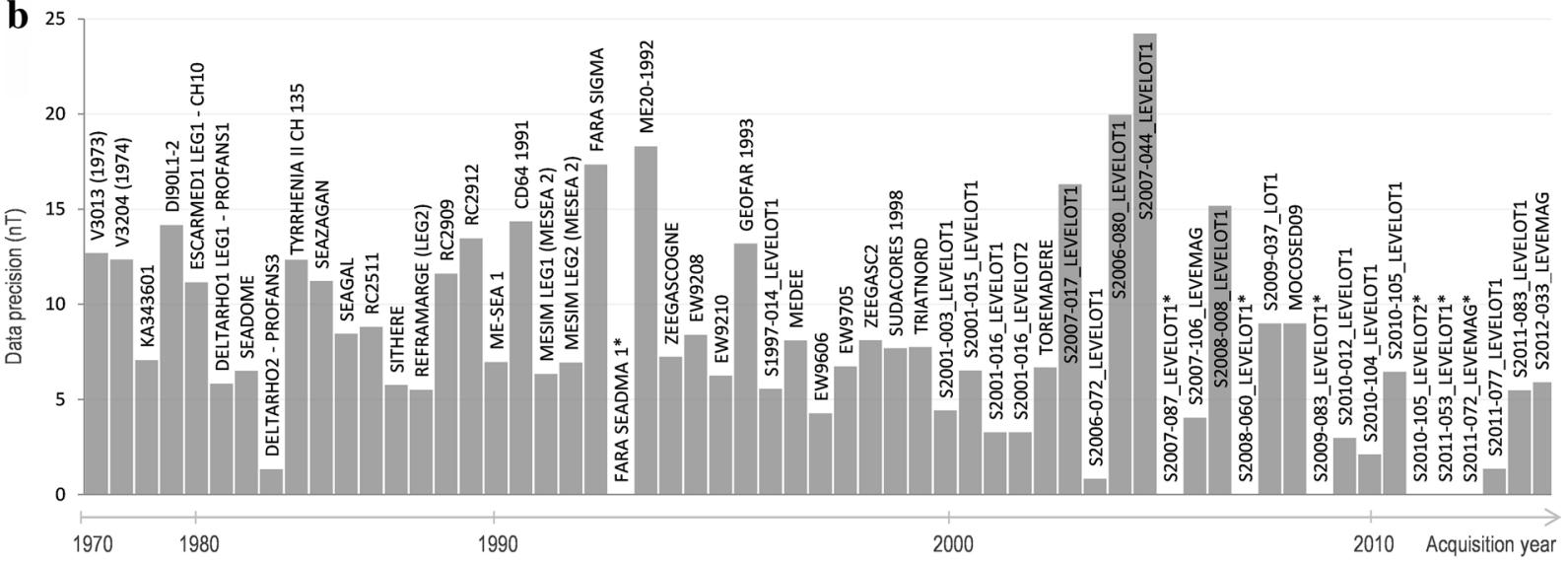

Fig. 2 Marine datasets used in the study. a Map showing the areas of interest selected for statistics with models (see Table 3). b Summary diagram showing selected datasets sorted by acquisition year (in abscissa). The data precision estimated by differences at crossover points is indicated in ordinate. The precision of the datasets marked with a star is undetermined (mainly due to a lack of crossover points), but estimated to be lower than $30 \mathrm{nT}$

Table 2 Number of surveys and magnetic measurements (after filtering and sub-sampling) used in the study

\begin{tabular}{lll}
\hline Area of interest & $\begin{array}{l}\text { Number } \\
\text { of surveys }\end{array}$ & $\begin{array}{l}\text { Number } \\
\text { of magnetic } \\
\text { measurements }\end{array}$ \\
\hline NEAWM area (i.e. full dataset) & 71 & $1,070,035$ \\
Mid-Atl. ridge 20-45 N & 17 & 362,564 \\
Canarian Isl. to offshore west Portugal & 16 & 227,584 \\
Bay of Biscay & 5 & 47,609 \\
English Channel to North Sea & 26 & 138,024 \\
W. Mediterranean Sea & 23 & 294,254 \\
\hline
\end{tabular}

area. Several spatial and amplitude discrepancies can be observed however: (1) Differences computed for SH degree 12 models are a few nanoteslas greater than those for $\mathrm{SH}$ degree 13. Moreover, maps of differences in $\mathrm{SH}$ degree 12 exhibit higher wavelengths and a noticeable inverse polarity (see for example, the south of Africa or the alternation of positive and negative differences in the South Atlantic Ocean in Fig. 3) compared with SH degree 13 maps. All these observations are consistent with the lower degree of spherical harmonics; and (2) the COV-OBS.x1 model seems to be relatively equivalent to HDGM2016, EMM2015 and POMME-9 models for the 
date $01 / 01 / 2010$ with average differences of a few nanoteslas. However, the $01 / 01 / 2015$ forecast for the COV-OBS. $\mathrm{x} 1$ model is not robust and seems to be inconsistent with other models (see Fig. 3d). Mean differences are one to two orders of magnitude higher and are estimated to be about $97 \pm 260 \mathrm{nT}$ at a global scale and $-4 \pm 140 \mathrm{nT}$ for the NEAWM area.

These results are coherent with the conclusions of Thébault et al. (2015b) for the evaluation of candidate models for IGRF-12. The authors underline that all submitted models are not different enough to be rejected with differences generally much less than $10 \mathrm{nT}$. Amongst them, parent or derived models are used in the present study (i.e. CM, COV-OBS, WMM); the other ones are identified as CHAOS5 from DTU Space (Finlay et al. 2015) or as one-time initiatives for example from BGS (Hamilton et al. 2015), GFZ (Lesur et al. 2015) and IPGP/CEA/LPG Nantes (Fournier et al. 2015; Vigneron et al. 2015; Saturnino et al. 2015). Based on the works of Thébault et al. (2015b), the internal component to $\mathrm{SH}$ degree 13 of all these models can be considered as equivalent.

Inclination and declination of the internal and anomaly fields Inclination and declination grids estimated from global magnetic models are compared with those calculated from IGRF-12 taken as the reference (see Additional file 2; Figs. 4 and 5). Differences between HDGM2016 and EMM2015 are also evaluated.

Differences in inclination and declination between internal HDGM2016core, WMM2015 and IGRF-12 are almost negligible, with means and standard deviations estimated at less than $0.01^{\circ}$.

Anomalously high differences in inclination and declination, up to $0.7^{\circ} \pm 0.7^{\circ}$ on average, are observed between EMM2015 and both IGRF-12 and HDGM2016. Those can be explained by doubtful negative inclination and declination values (i.e. located south of the geomagnetic equator for inclination and in the main part of the Atlantic and Indian Oceans and northeast Asia for declination, see Additional file 3) given by the lithospheric EMM2015 model. Additional tests did not identify any problems for the previous version of the product (EMM2010). Inclination and declination parameters are reflected correctly with results close to other models. Defaults, probably due to digital coding, are only observed for the 2015 version. However, for the NEAWM area, inclination values estimated from EMM2015 are consistent with those of the HDGM2016 model. Differences between HDGM2016 and IGRF-12 are small on average with $0.1^{\circ}$ and $0.2^{\circ}$ standard deviations for inclination and declination, respectively. They are obviously high locally with extrema of up to $6^{\circ}$. Discrepancies for POMME-9 are about half in amplitude (standard deviations estimated at $0.05^{\circ}$ and $0.1^{\circ}$ for inclination and declination, respectively) which is consistent overall considering the model's low resolution.

\section{Intensity of the anomaly field}

The intensity of the anomaly field estimated using the HDGM2016, EMM2015, EMAG2v3 and WDMAM models is evaluated up to SH degree 720 or with the equivalent $0.5^{\circ}$ grid spacing (see Additional file 4; Figs. 6 and 7).

HDGM2016 and EMM2015 up to SH degree 720 can be considered as equivalent. Firstly, differences between these two models are small for all dates and extents, estimated at about few nanoteslas. They appear to be relatively higher for the date 01/01/2015 (only about $1 \mathrm{nT}$ higher on average). The difference map suggests a longwave residual signal that can be explained by the use of more complete SWARM datasets for the HDGM2016 model, whereas only data up to 2014.8 are considered for EMM2015 (Fig. 6a). Secondly, spectral content is consistent for both models at a global scale and for the NEAWM area (Fig. 6b). Finally, differences with EMAG2v3 and WDMAM are comparable with standard deviations of about $75 \mathrm{nT}$ for EMAG2v3 and $110 \mathrm{nT}$ for WDMAM. Statistics thus show that differences between SH models and anomaly grids, at $0.5^{\circ}$ in resolution, are one and a half times higher for WDMAM. Differences between EMAG2v3 and WDMAM are on average estimated at $5 \pm 100 \mathrm{nT}$ with extrema higher than $1300 \mathrm{nT}$ mainly located in the mid-Atlantic ridge. These values can be explained by WDMAM's richer spectral content compared to the other models (Fig. 7d).

\section{Comparison with marine datasets}

Statistics on differences between the HDGM2016, EMAG2v3 and WDMAM models and marine data are summarized in Table 3. Maps of the most significant differences between HDGM2016 (estimated up to SH degree 720 with $0.5^{\circ}$ grid spacing) and processed filtered marine data or WDMAM (with full grid spacing of $3 \mathrm{arc}$ minutes) and unfiltered data are shown in Fig. 8.

(See figure on next page.)

Fig. 3 Map of differences in intensity values of the internal (INT) field estimated from WMM2015 (a), CM4 (b), HDGM2016 (c), COV-OBS.x1 (d) and IGRF-12 (reference) models up to SH degrees 12 and 13, at a global scale reduced by $30^{\circ}$ in latitude and $20^{\circ}$ in longitude (left, grid spacing: $1^{\circ}$ ) and for the NEAWM area (right, grid spacing: $0.5^{\circ}$ ) 
a WMM2015-IGRF-12, INT/12, 01/01/2015
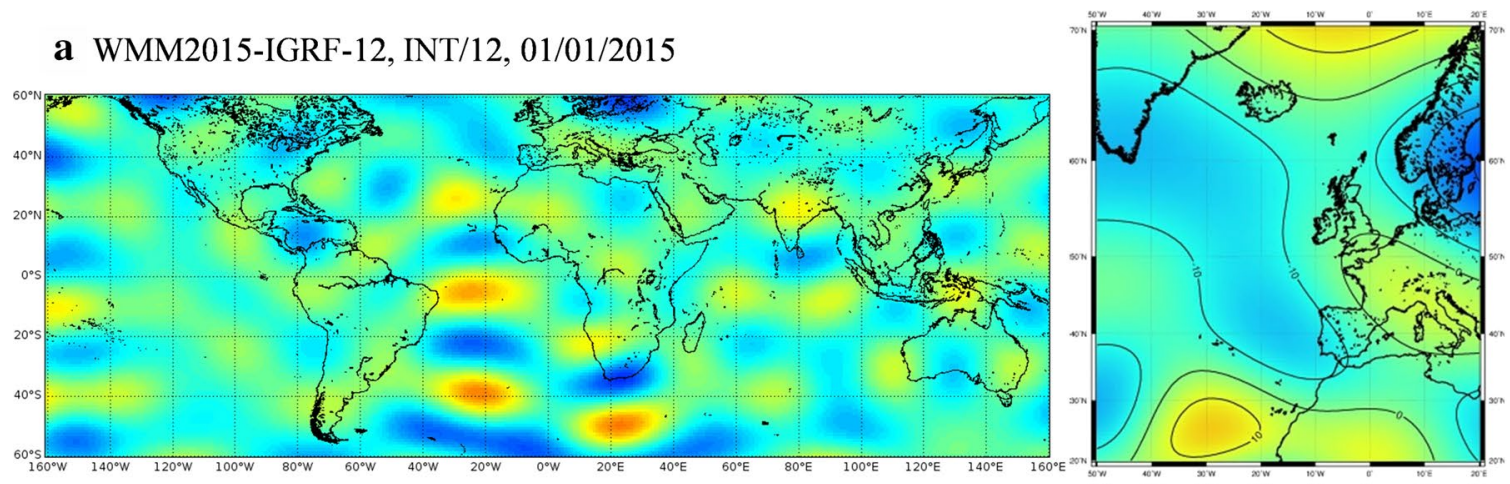

b CM4-IGRF-12, INT/13, 01/01/2000


c HDGM2016-IGRF-12, INT/13, 01/01/2015
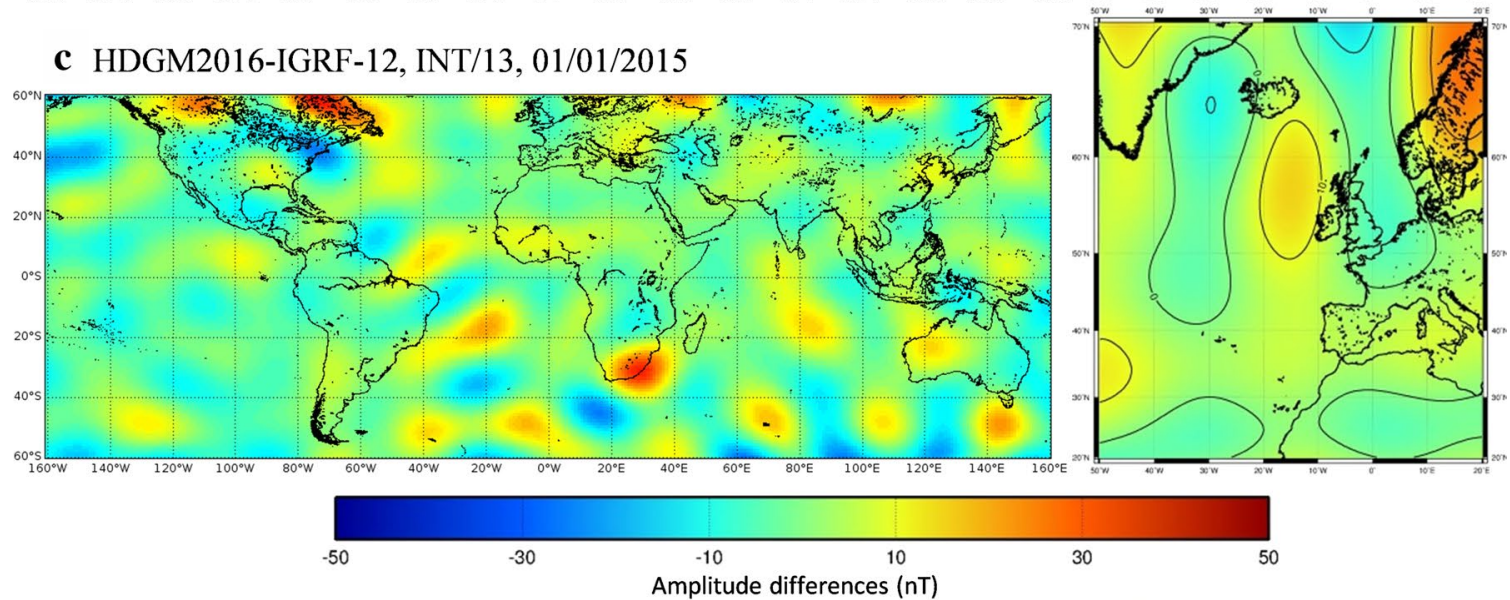

Amplitude differences (nT)

d COV-OBS.x1-IGRF-12, INT/13, 01/01/2015






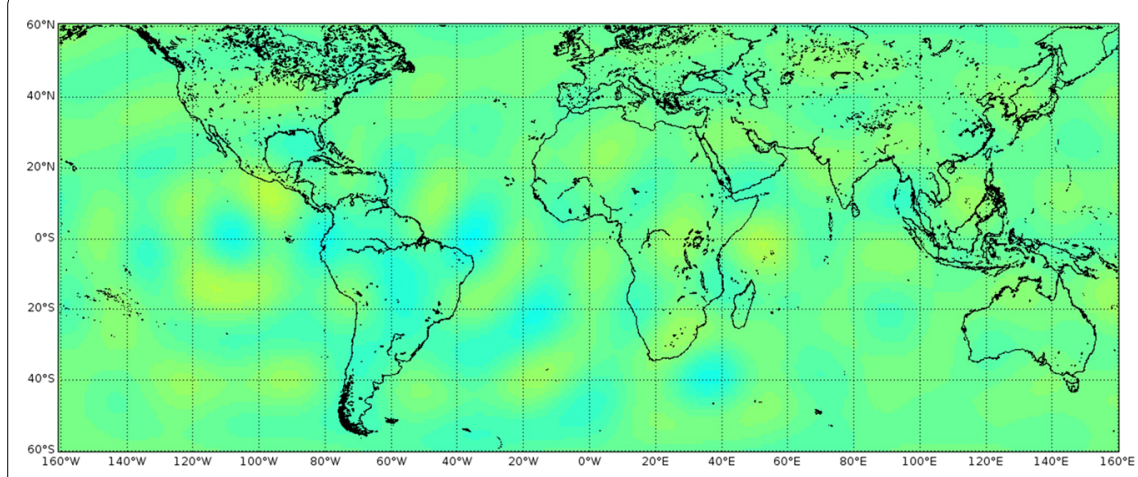

a HDGMcore2016-IGRF-12, 01/01/2015
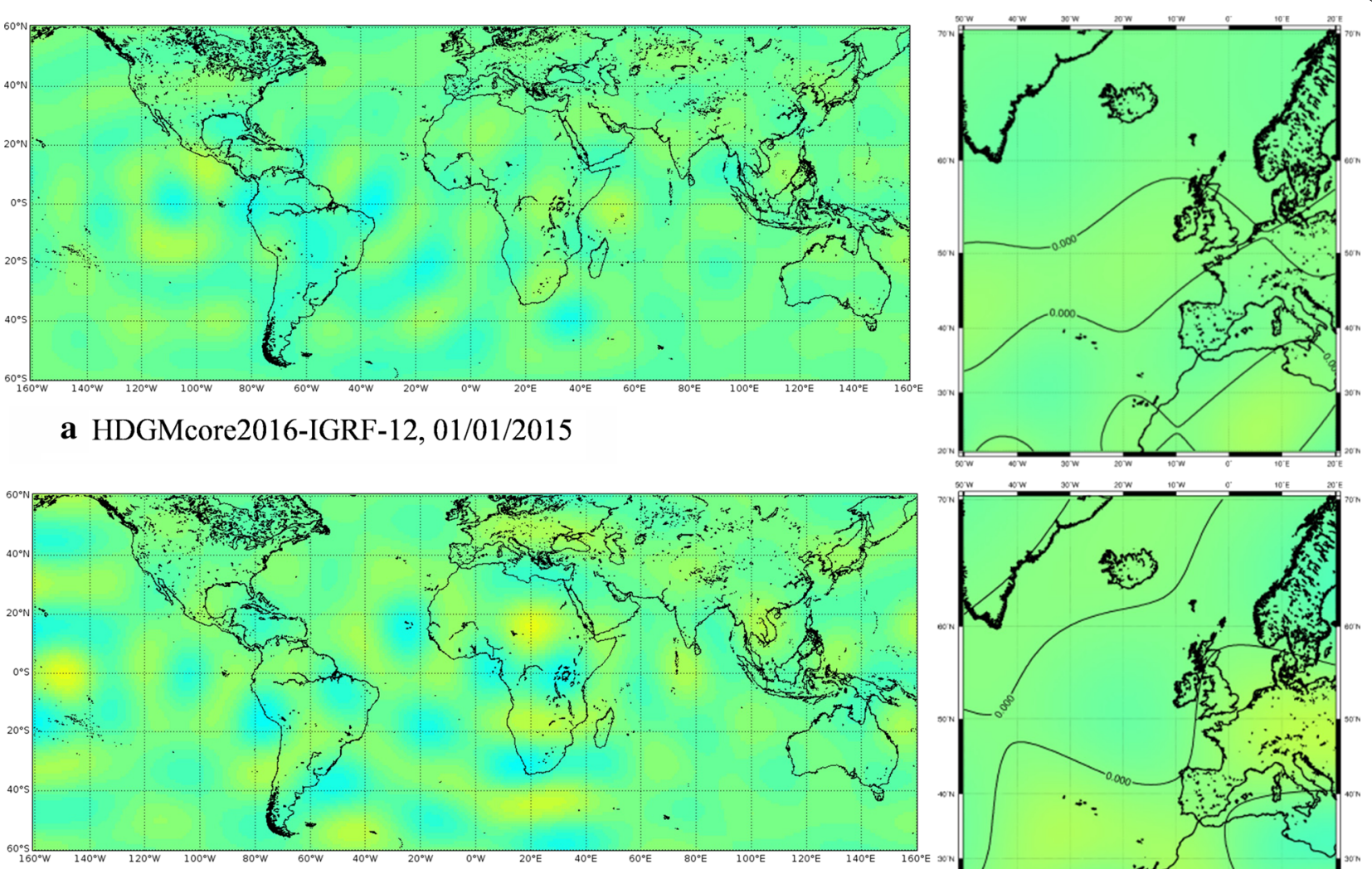

b WMM2015-IGRF-12,01/01/2015
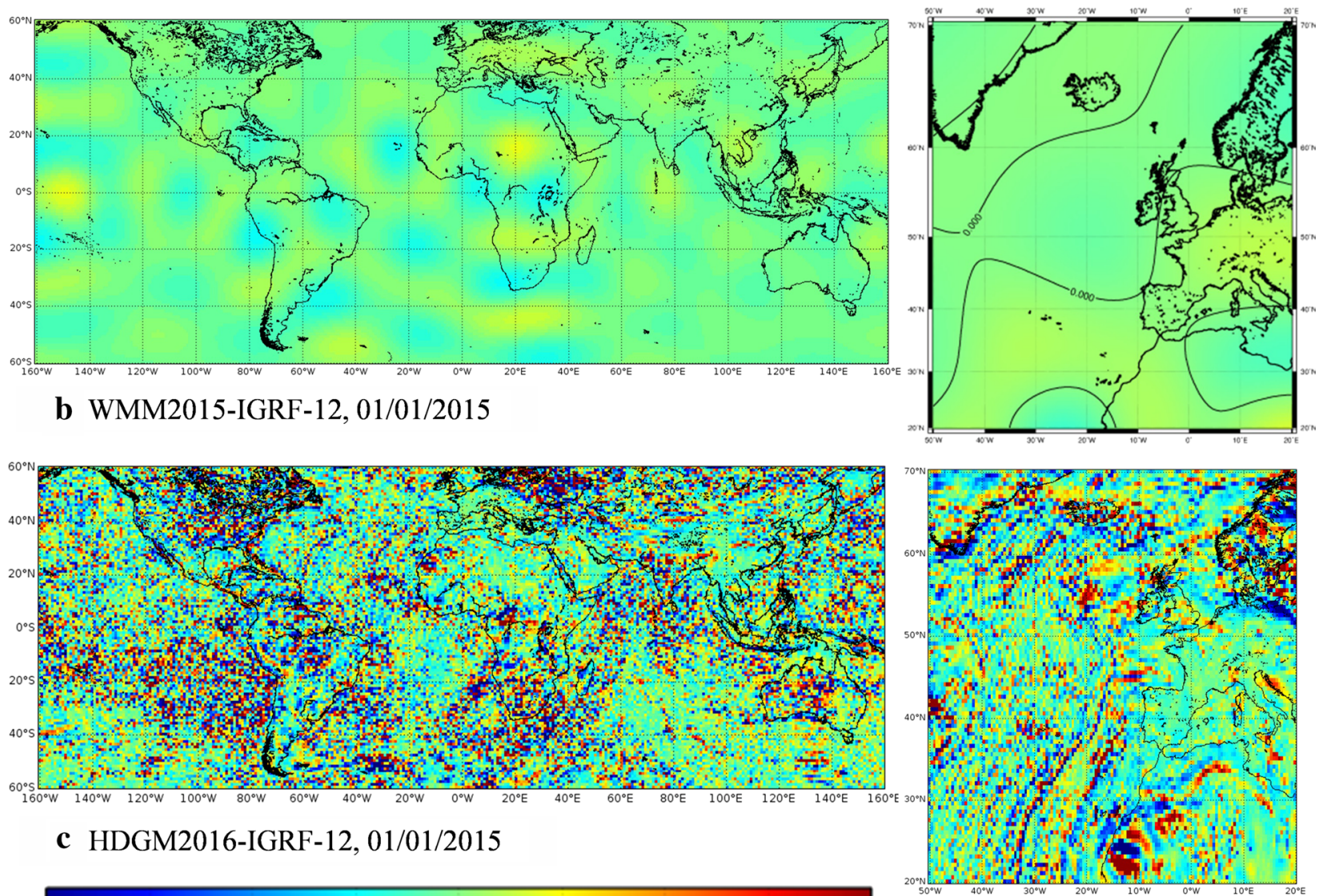

c HDGM2016-IGRF-12, 01/01/2015

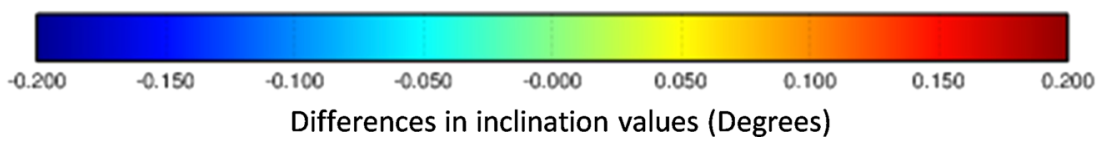

Fig. 4 Maps of differences in inclination values estimated from HDGM2016core (a), WMM2015 (b), HDGM2016 (c) and IGRF-12 (reference) models at a global scale reduced by $30^{\circ}$ in latitude and $20^{\circ}$ in longitude (left, grid spacing: $1^{\circ}$ ) and for the NEAWM area (right, grid spacing: $0.5^{\circ}$ )

Up to SH degree 720 (or through equivalent grid spacing of $0.5^{\circ}$ ), differences between global anomaly models and filtered marine data are minimized for HDGM2016 (for all dates) and EMAG2v3. Statistics are relatively similar for both models whether for the NEAWM area or geographical sub-areas. Mean differences for the NEAWM area are estimated at about a few nanoteslas with relatively high standard deviations of about $65 \mathrm{nT}$. Differences seem to be more significant for WDMAM with about $80 \mathrm{nT}$ in standard deviations for the NEAWM 




a HDGMcore2016-IGRF-12, 01/01/2015
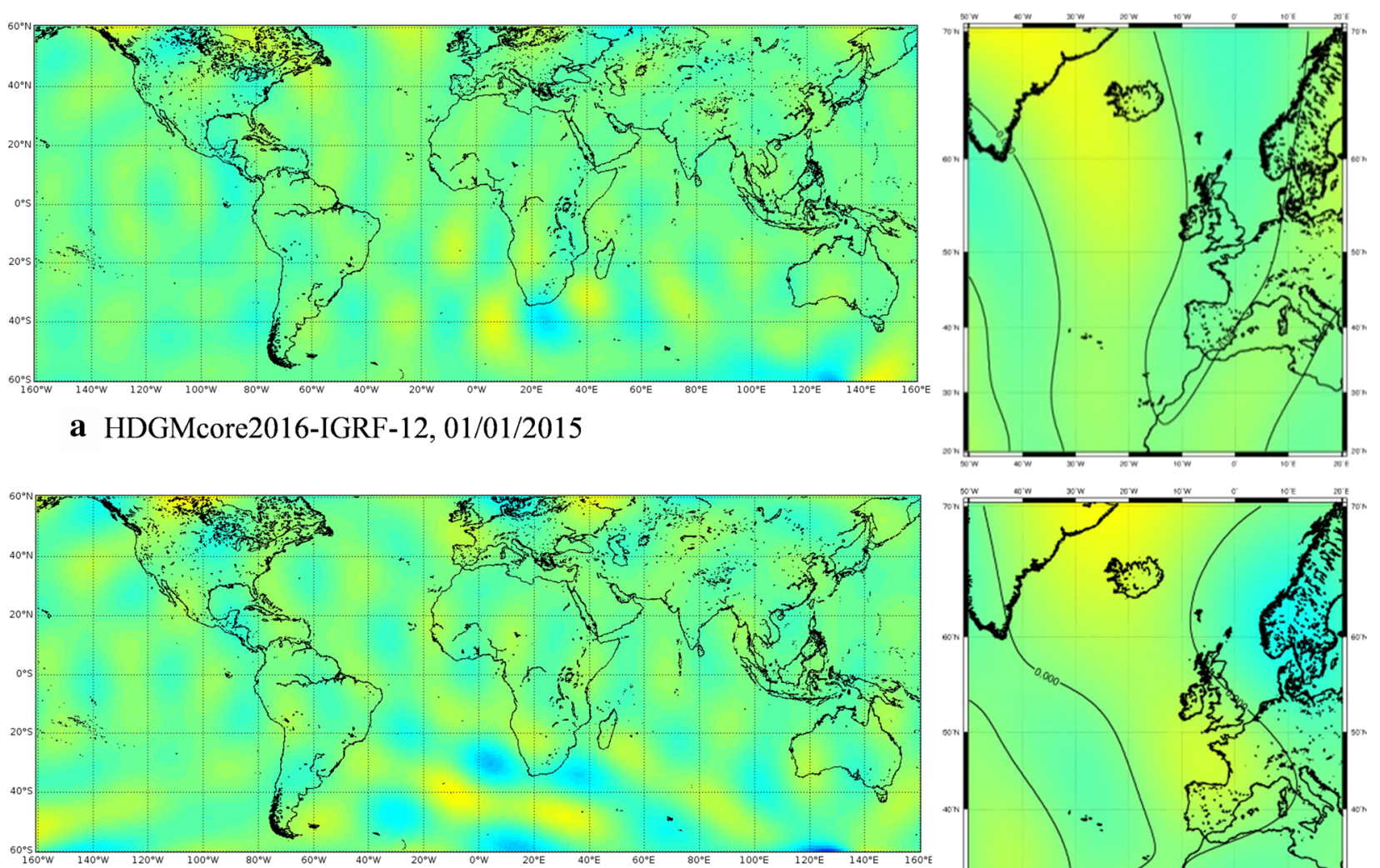

b WMM2015-IGRF-12, 01/01/2015
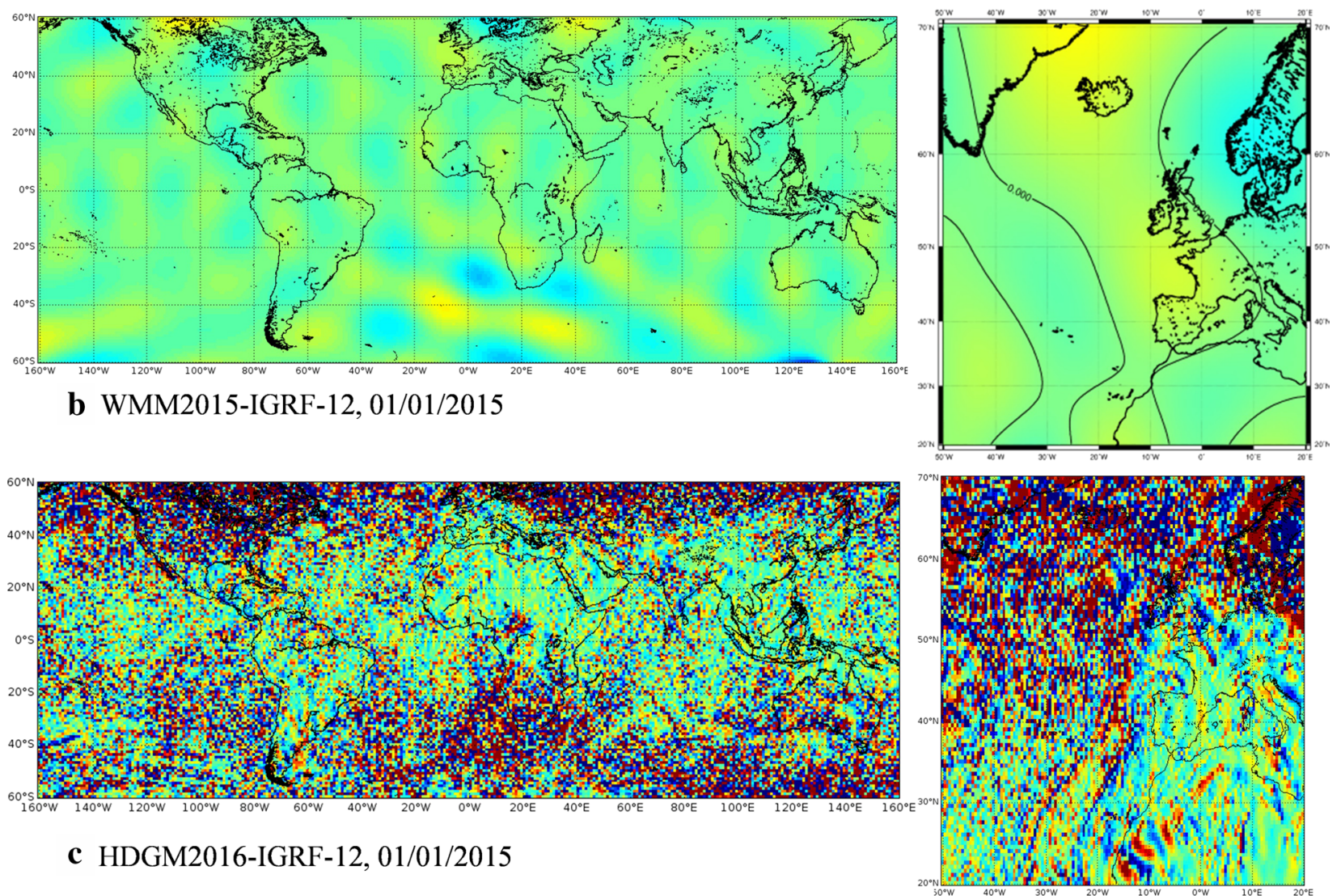

c HDGM2016-IGRF-12, 01/01/2015

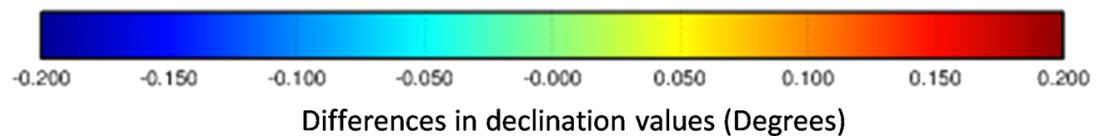

Fig. 5 Maps of differences in declination values estimated from HDGM2016core (a), WMM2015 (b), HDGM2016 (c) and IGRF-12 (reference) models at a global scale reduced by $30^{\circ}$ in latitude and $20^{\circ}$ in longitude (left, grid spacing: $1^{\circ}$ ) and for the NEAWM area (right, grid spacing: $0.5^{\circ}$ )

area. Most significant discrepancies are observed along the mid-Atlantic ridge where HDGM2016 and EMAG2v3 appear to be much closer to the marine data than WDMAM, with increases of more than $30 \mathrm{nT}$. High differences are also correlated with strong magnetic gradients observed along the Tore-Madeira rise (see Fig. 8), where HDGM2016, EMAG2v3 and WDMAM models are statistically equivalent.

In contrast, at full grid spacing, the 3 arc minutes WDMAM model is closer to unfiltered marine data. 


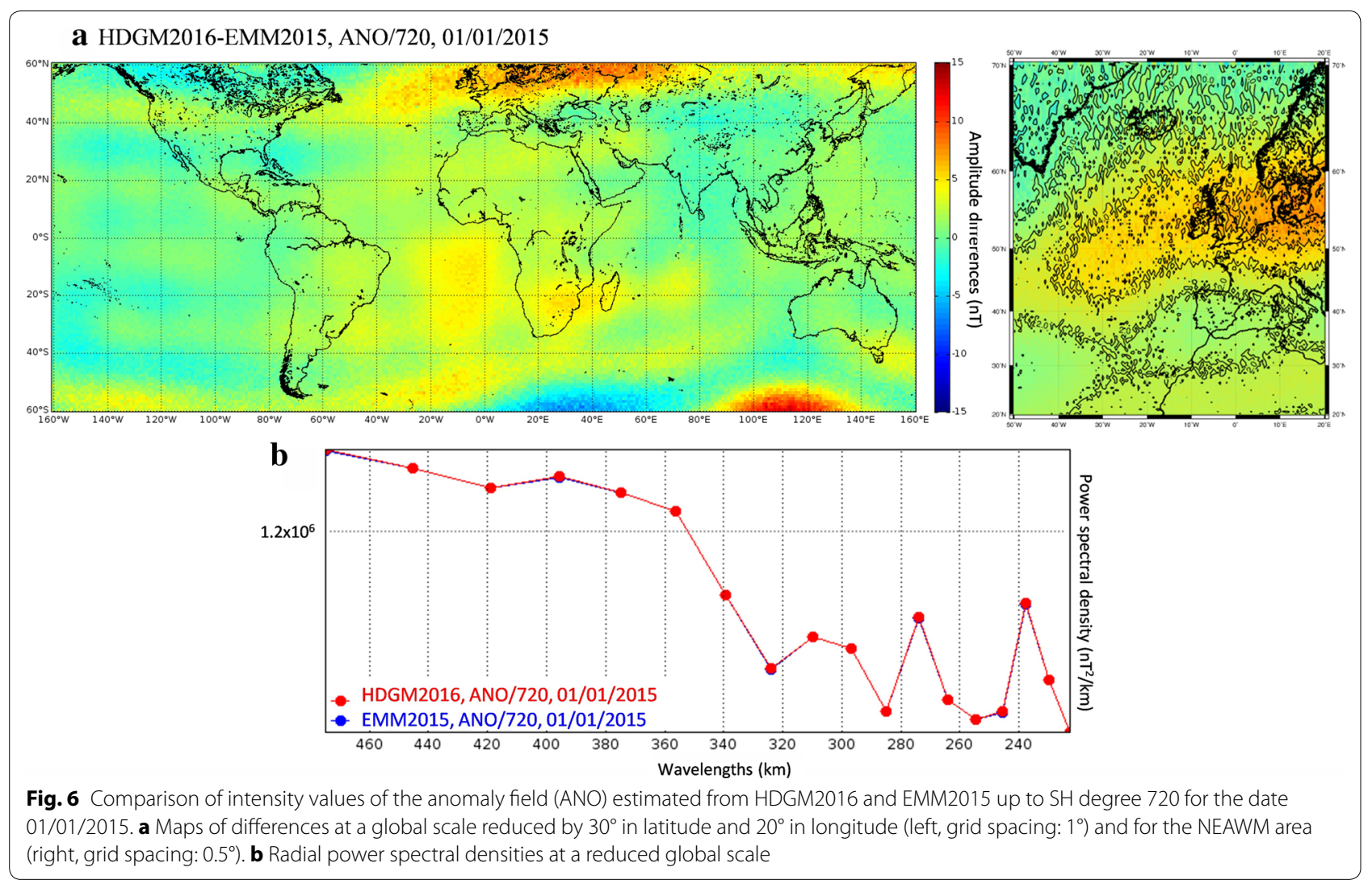

Apart from the English Channel to North Sea sub-area, differences between WDMAM and data decrease as resolution increases. Considering all data for the NEAWM area, standard deviations decrease from about $80 \mathrm{nT}$ at $0.5^{\circ}$ in resolution to about $70 \mathrm{nT}$ for high resolution. By contrast, differences with the 2 arc minutes EMAG2v3 model significantly increase for the mid-Atlantic ridge and English Channel to North Sea sub-areas and consequently for the NEAWM area. Standard deviations for the NEAWM area are estimated at about $90 \mathrm{nT}$ for high resolution compared to about $70 \mathrm{nT}$ at $0.5^{\circ}$ in resolution.

Best statistics observed for EMAG2v3 for $0.5^{\circ}$ grid spacing and for WDMAM at full resolution are notable, as both models are globally based on the same datasets and precompiled grids. A noteworthy difference is the use of more realistic synthetic magnetic anomalies generated from ocean spreading (Lesur et al. 2016) for WDMAM, in unsurveyed areas. This may partly explain the more favourable statistics for the 3-arc-minute WDMAM model in the mid-Atlantic ridge and the Canary Islands to offshore west Portugal sub-areas. Whatever the resolution, differences between models and data on the Bay of Biscay and the western Mediterranean Sea sub-areas are relatively high (with standard deviations of about $35-50 \mathrm{nT}$ ). It is not disturbing considering the precision of the marine data (see Fig. 2). On the contrary, EMAG2v3 and WDMAM inadequately characterize the magnetic signal at high resolution in the English Channel to North Sea continental shelf. The main differences in this area can be explained by the exclusive assimilation of the French longer-wave aeromagnetic data in the global anomaly models (Le Mouël 1970).

\section{Limitations of the comparative study}

The following limitations should be kept in mind when analysing these results:

- The study only focusses on the intensity of the magnetic field or of the anomaly field and the inclination/declination parameters calculated for the dates 01/01/2010, 01/01/2015 and for the CM4 model, $01 / 01 / 2000$. It gives an overview of the behaviour of the models, but the study could benefit from a larger temporal coverage.

- The comparison of the internal component of the geomagnetic field is performed by filtering the spectral content of the considered models with a Butter- 




Table 3 Differences in intensity values of the anomaly field (ANO) in nT estimated from HDGM2016 up to SH degree 720, EMAG2v3 and WDMAM anomaly grids and marine datasets gathered by area of interest

\begin{tabular}{|c|c|c|c|c|c|c|}
\hline \multirow[t]{2}{*}{ Area of interest } & \multicolumn{6}{|l|}{ Model } \\
\hline & $\begin{array}{l}\text { HDGM2016 } \\
01 / 01 / 2010 \\
\text { ANO/720 0.5 }\end{array}$ & $\begin{array}{l}\text { HDGM2016 } \\
01 / 01 / 2015 \\
\text { ANO/720 0.5 }\end{array}$ & EMAG2v3 $3^{\mathrm{a}} 0.5^{\circ}$ & WDMAM $^{\mathrm{a}} 0.5^{\circ}$ & EMAG2v3 $3^{b} 2^{\prime}$ & WDMAM $^{\mathrm{b}} 3^{\prime}$ \\
\hline NEAWM area (i.e. full dataset) & $-1.50 \pm 65.87$ & $-5.40 \pm 65.71$ & $-5.75 \pm 67.33$ & $1.01 \pm 81.44$ & $-5.48 \pm 89.14$ & $-0.58 \pm 69.41$ \\
\hline Mid-Atl. ridge $20-45^{\circ} \mathrm{N}$ & $-5.09 \pm 88.61$ & $-9.11 \pm 88.69$ & $-13.12 \pm 91.11$ & $-8.27 \pm 118.65$ & $-8.74 \pm 132.35$ & $-2.59 \pm 101.25$ \\
\hline $\begin{array}{l}\text { Canarian Isl. to offshore west } \\
\text { Portugal }\end{array}$ & $-12.99 \pm 62.96$ & $-15.73 \pm 62.65$ & $-13.34 \pm 59.97$ & $-5.67 \pm 62.04$ & $-13.24 \pm 55.94$ & $-7.66 \pm 42.79$ \\
\hline Bay of Biscay & $-0.50 \pm 37.81$ & $-6.42 \pm 37.87$ & $0.72 \pm 37.86$ & $6.52 \pm 43.02$ & $2.14 \pm 36.41$ & $3.20 \pm 34.32$ \\
\hline English Channel to North Sea & $18.17 \pm 36.05$ & $11.60 \pm 36.05$ & $8.65 \pm 32.44$ & $9.52 \pm 35.09$ & $2.73 \pm 60.45$ & $-1.37 \pm 57.19$ \\
\hline W. Mediterranean Sea & $2.01 \pm 42.48$ & $-1.03 \pm 42.39$ & $1.00 \pm 49.22$ & $12.49 \pm 50.51$ & $-0.49 \pm 49.47$ & $7.03 \pm 37.75$ \\
\hline
\end{tabular}

Marine data are processed and filtered ${ }^{\mathrm{a}}$ or only processed ${ }^{\mathrm{b}}$ to give spectral content comparable to that of the models

worth filter. The filtering is questionable, as it is at the origin of long-wave residual signals making it difficult to interpret the difference models. Extensive use of the classically applied truncation method (see for example Barthelmes and Köhler 2016) would enable a more robust comparative analysis. 







\section{Conclusions}

We have presented a comparison of nine global geomagnetic models and their evaluation using an external marine dataset processed according Shom's methodology. Results can be interpreted in the form of a summary diagram that provides a direct overview of the quality of the models (Fig. 9).

The main findings after comparing global magnetic models are:

\section{- Up to SH degree 13:}

- The WMM2015, EMM2015, HDGM2016, POMME-9, CM4 and IGRF-12 models quite similarly reflect the internal component of the geomagnetic field with relative differences in intensity value of less than $10 \mathrm{nT}$ (for an order of magnitude of $10^{5} \mathrm{nT}$ ). Differences in inclination and declination values are estimated to be lower than $0.1^{\circ}$ for WMM2015, HDGM2016core and IGRF-12 models.

- The COV-OBS.x1 model is interpreted to be equivalent to others but solely for the date $01 / 01 / 2010$. The computation for the date $01 / 01 / 2015$ is provisional and consequently less robust.

- According to the work of Thébault et al. (2015b), our results can be generalized to candidate models used to produce the reference model IGRF-12, and in particular to CHAOS5 model (Finlay et al. 2015).

These results demonstrate that any model can be used with insignificant errors to compute raw anomalies from total field measurements by removing the internal component of the Earth's magnetic field.

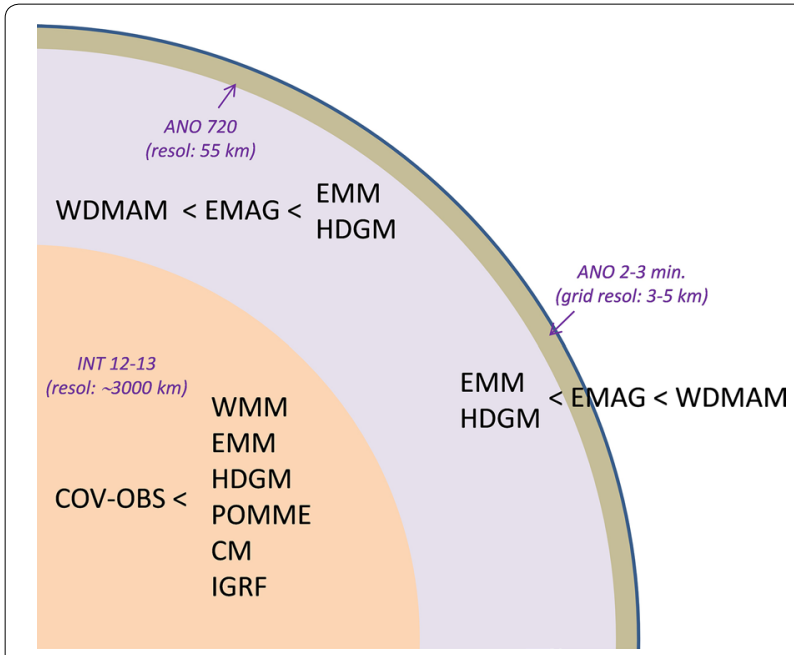

Fig. 9 Interpretative summary diagram illustrating the results of the comparison between global magnetic models and the comparison with marine data
- Up to SH degree 720 or $0.5^{\circ}$ equivalent grid spacing:

- HDGM2016 and EMM2015 are similar with low differences of about a few nanoteslas, for all dates and extents, and consistent spectral content. Only long-wave variations are observed and are explained by the inclusion of new SWARM data in the 2016 revision of the HDGM model. HDGM2016 and EMM2015 are thus equivalent overall for both internal and lithospheric components. This result is not surprising because they are built according to the same methods and based on almost the same datasets (see Table 1).

- The EMM2015 model is doubtful with respect to negative inclination and declination values. For the NEAWM area, the inclination grid is consistent and comparable with the grid derived from HDGM2016. Inclination and declination grids computed from the EMM2010 model are also consistent. EMM inconsistencies for both parameters seem to be observed only for the 2015 version.

- Differences between HDGM2016 and EMM2015 comparatively to EMAG2v3 and WDMAM are significant but about one and a half times more for WDMAM (standard deviations of about $110 \mathrm{nT}$ compared to $75 \mathrm{nT}$ for EMAG2v3). Direct differences between EMAG2v3 and WDMAM are about $5 \pm 100 \mathrm{nT}$ with extrema higher than $1300 \mathrm{nT}$ located in the mid-Atlantic ridge.

The evaluation of the global lithospheric HDGM2016, EMAG2v3 and WDMAM models by comparison with marine data for the NEAWM area gives the following information:

- Up to $\mathrm{SH}$ degree 720 or $0.5^{\circ}$ equivalent grid spacing, mean differences between processed and filtered data and the HDGM2016 and EMAG2v3 models are the lowest and are estimated at about a few nanoteslas with standard deviations of about $65 \mathrm{nT}$.

- In contrast, at full grid spacing, the 3-arc-minute WDMAM model minimizes differences with processed unfiltered data. They slightly decrease as resolution increases (increase of $10 \mathrm{nT}$ in standard deviation between $0.5^{\circ}$ and $3 \mathrm{~min}$.), while they significantly increase for EMAG2v3 (decrease of $20 \mathrm{nT}$ between $0.5^{\circ}$ and $2^{\prime}$ ). These results suggest that the priority should be given to WDMAM for levelling and evaluating marine datasets and for computing enhanced high-resolution regional magnetic maps. 


\section{Additional files}

Additional file 1. Comparative statistical analysis of differences in intensity values of the internal field (INT) estimated up to SH degrees 12 and 13 from global models (A) at a global scale reduced by $30^{\circ}$ in latitude and $20^{\circ}$ in longitude (grid spacing: $1^{\circ}$ ) and (B) for the NEAWM area (grid spacing: $0.5^{\circ}$.

Additional file 2. Comparative statistical analysis of differences in inclination and declination values estimated (A) at a global scale reduced by $30^{\circ}$ in latitude and $20^{\circ}$ in longitude (grid spacing: $1^{\circ}$ ) and (B) for the NEAWM area (grid spacing: $0.5^{\circ}$ ).

Additional file 3. Maps of differences in inclination and declination values estimated from EMM2015 (A) and EMM2010 (B) and IGRF-12 (reference) models at a global scale reduced by $30^{\circ}$ in latitude and $20^{\circ}$ in longitude (grid spacing: $1^{\circ}$ ). Probably due to digital coding, the EMM2015 lithospheric model is doubtful for negative values of inclination and declination. Tests did not identify any problems for the previous version of the product (EMM2010).

Additional file 4. Comparative statistical analysis of differences in intensity values of the anomaly field (ANO) estimated up to SH degree 720 from HDGM2016 and EMM2015 and derived from EMAG2V3 and WDMAM (A) at a global scale reduced by $30^{\circ}$ in latitude and $20^{\circ}$ in longitude (grid spacing: $1^{\circ}$ ) and (B) for the NEAWM area (grid spacing: $0.5^{\circ}$ ).

\section{Abbreviations}

ANO: anomaly field of the Earth's magnetic field; BGS: British Geological Survey; CEA: Commissariat à l'énergie atomique et aux énergies alternatives, France; CIRES: Cooperative Institute for Research in Environmental Sciences: CGMW: Commission for the Geological Map of the World; CM: comprehensive model of the geomagnetic field; DGA: Direction Générale de l'Armement (French Defence Procurement Agency); DTU: Danish Technical University; EMAG: Earth Magnetic Anomaly Grid; EMM: enhanced magnetic model; ESA: European Space Agency; GFZ: GeoForschungZentrum Potsdam; HDGM: High Definition Geomagnetic Model; IAGA: International Association of Geomagnetism and Aeronomy; IPGP: Institut de Physique du Globe de Paris, University of Sorbonne Paris Cité, France; IGRF: International Geomagnetic Reference Field; INT: internal component of the Earth's magnetic field; ISTerre: Institute of Earth Sciences, University of Grenoble, France; LF: low frequency anomaly (only corrected from diurnal variations); LF + HF: low plus high frequency anomaly (corrected from diurnal and agitation variations); LPG: Laboratoire de Planétologie et Géodynamique, University of Nantes, France; MSL: mean sea level; NASA: National Aeronautics and Space Administration; NCEl: National Centers for Environmental Information; NEAWM: north-eastern Atlantic Ocean and western Mediterranean Sea (area of interest); NATO: North Atlantic Treaty Organization; NGA: US National Geospatial-intelligence Agency; NOAA: National Oceanic and Atmospheric Administration; PGL: Planetary Geodynamics Laboratory; POMME: Potsdam Magnetic Model of the Earth; SH: spherical harmonics; Shom: Service Hydrographique et Océanographique de la Marine (French Hydrographic and Oceanographic Service); SISMER: Systèmes d'Informations Scientifiques pour la MER (French National Oceanographic Data Centre);WMM: World Magnetic Model.

\section{Authors' contributions}

OJF is the main contributor to this study (processing, interpretation, summary/ reporting). RD and LLMF worked as expert supervisors and project managers. All authors read and approved the final manuscript.

\section{Authors' information}

Shom's geophysical department specializes in marine geophysical data processing and interpretation. It focusses on potential methods (gravity and magnetism).

\section{Acknowledgements}

We would like to thank Sylvain Lucas (Shom) for his efforts in processing marine magnetic data but also Corinne Salaün and Thierry Schmitt (Shom) for preliminary and final reviews. This work would not have been possible without many scientists and crews (from Shom, Groupe Hydrographique et Océanographique de l'Atlantique (GHOA) and external international organizations) who collected and made marine magnetic data available. The paper benefited from helpful reviews and comments from two anonymous reviewers.

\section{Competing interests}

The authors declare that they have no competing interests.

\section{Availability of data and materials}

The geomagnetic field models used in this study are publicly available from the following links: IGRF-12 (https://www.ngdc.noaa.gov/IAGA/vmod/igrf. html), WMM2015 (https://www.ngdc.noaa.gov/geomag/WMM/DoDWM M.shtml), COV-OBS.x1 (http://www.spacecenter.dk/files/magnetic-models/ COV-OBSX1/), CM4 (http://planetary-mag.net/earth_interface.html), POMME-9 (http://www.geomag.org/models/pomme9.html), EMM2015 (https://www. ngdc.noaa.gov/geomag/EMM/), EMAG2v3 (https://www.ngdc.noaa.gov/ geomag/emag2.html), WDMAM (http://wdmam.org/). The HDGM2016 model is under licence (https://www.ngdc.noaa.gov/geomag/HDGM/index.html). External raw marine magnetic datasets are available from SISMER's web portal (https://www.ifremer.fr/sismer). Some external processed datasets are also available from NCEl's web portal (https://maps.ngdc.noaa.gov/viewers/geoph ysics/).

\section{Consent for publication \\ Not applicable.}

\section{Ethics approval and consent to participate}

Not applicable.

\section{Funding}

This study has been supported by funding from Direction Générale de I'Armement (French Defence Procurement Agency) through the project "EA ENVGEO2".

\section{Publisher's Note}

Springer Nature remains neutral with regard to jurisdictional claims in published maps and institutional affiliations.

\section{Received: 22 January 2018 Accepted: 11 June 2018}

Published online: 22 June 2018

\section{References}

Alken P, Maus S, Chulliat A, Manoj C (2015) NOAA/NGDC candidate models for the 12th generation International Geomagnetic Reference Field. Earth Planets Space 67:68. https://doi.org/10.1186/s40623-015-0215-1

Backus G, Parker R, Constable C (1996) Foundations of geomagnetism. Cambridge University Press, Cambridge

Barthelmes F, Köhler W (2016) International Centre for Global Earth Models (ICGEM). In: Drewes H, Kuglitsch F, Adám J et al (eds) The Geodesists Handbook 2016. J Geod 90:907-1205. https://doi.org/10.1007/s0019 0-016-0948-z

Burg JP (1975) Maximum entropy spectral analysis. Ph.D. thesis, Stanford University

Chulliat A, Macmillan S, Alken P, Beggan C, Nair M, Hamilton B, Woods A, Ridley V, Maus S, Thomson A (2015) The US/UK World Magnetic Model for 2015-2020. https://doi.org/10.7289/v5tb14v7

Defense Mapping Agency (1993) Military specification for World Magnetic Model (WMM). Document MIL-W-89500

Dyment J, Choi Y, Hamoudi M, Lesur V, Thébault E (2015) Global equivalent magnetization of the oceanic lithosphere. Earth Planet Sci Lett 430:54-65. https://doi.org/10.1016/j.epsl.2015.08.002

Finlay CC, Olsen N, Tøffner-Clausen L (2015) DTU candidate field models for IGRF-12 and the CHAOS-5 geomagnetic field model. Earth Planets Space 67:114. https://doi.org/10.1186/s40623-015-0274-3

Fournier A, Aubert J, Thébault E (2015) A candidate secular variation model for IGRF-12 based on Swarm data and inverse geodynamo modelling. Earth Planets Space 67(1):81. https://doi.org/10.1186/s40623-015-0245-8 
Gillet N, Jault D, Finlay CC, Olsen N (2013) Stochastic modeling of the Earth's magnetic field: inversion for covariances over the observatory era. Geochem Geophys Geosyst 14:766-786. https://doi.org/10.1002/ggge.20041

Gillet N, Barrois O, Finlay CC (2015) Stochastic forecasting of the geomagnetic field from the COV-OBS.X1 geomagnetic field model, and candidate models for IGRF-12. Earth Planets Space 67:71. https://doi.org/10.1186/ s40623-015-0225-Z

Hamilton B, Ridley VA, Beggan CD, Macmillan S (2015) The BGS magnetic field candidate models for the 12th generation IGRF. Earth Planets Space 67(1):69. https://doi.org/10.1186/s40623-015-0227-x

Langel RA (1987) The main field. In: Jacobs JA (ed) Geomagnetism, vol I. Academic Press, HBJ, New York

Le Mouël JL (1970) Le levé aéromagnétique de la France. Calcul des composantes du champ à partir des mesures de l'intensité. Ann Geophys 26(2):229-258

Lesur V, Rother M, Wardinski I, Schachtschneider R, Hamoudi M, Chambodut A (2015) Parent magnetic field models for the IGRF-12GFZ-candidates. Earth Planets Space 67(1):87. https://doi.org/10.1186/s40623-015-0273-4

Lesur V, Hamoudi M, Choi Y, Dyment J, Thébault E (2016) Building the second version of the World Digital Magnetic Anomaly Map (WDMAM). Earth Planets Space 68:1-13. https://doi.org/10.1186/s40623-016-0404-6

Lowes FJ (2000) An estimate of the errors of the IGRF/DGRF fields 1945-2000. Earth Planets Space 52:1207-1211

Maus S (2010) An ellipsoidal harmonic representation of Earth's lithospheric magnetic field to degree and order 720. Geochem Geophys Geosyst 11:Q06015. https://doi.org/10.1029/2010GC003026

Maus S, Rother M, Stolle C, Mai W, Choi S, Lühr H, Cooke D, Roth C (2006) Third generation of the Potsdam Magnetic Model of the Earth (POMME). Geochem Geophys Geosyst 7:Q07008. https://doi.org/10.1029/2006G C001269

Maus S, Sazonova T, Hemant K, Fairhead JD, Ravat D (2007) National Geophysical Data Center candidate for the World Digital Magnetic Anomaly Map. Geochem Geophys Geosyst 8:Q06017. https://doi.org/10.1029/2007G C001643

Maus S et al (2009) EMAG2: a 2-arc min resolution Earth Magnetic Anomaly Grid compiled from satellite, airborne, and marine magnetic measurements. Geochem Geophys Geosyst 10:Q08005. https://doi. org/10.1029/2009GC002471

Maus S, Manoj C, Rauberg J, Michaelis I, Lühr H (2010) NOAA/NGDC candidate models for the 11th generation International Geomagnetic Reference Field and the concurrent release of the 6 th generation Pomme magnetic model. Earth Planets Space 62:729-735. https://doi.org/10.5047/ eps.2010.07.006

Meyer B, Saltus R, Chulliat A (2016) EMAG2: Earth Magnetic Anomaly Grid (2-arc-minute resolution) Version 3. Model, National Centers for Environmental Information, NOAA. https://doi.org/10.7289/N5H70CVX

Meyer B, Chulliat A, Saltus R (2017) Derivation and error analysis of the Earth Magnetic Anomaly Grid at 2 arc min Resolution Version 3 (EMAG2v3). Geochem Geophys Geosyst 18:4522-4537. https://doi. org/10.1002/2017GC007280

Quesnel Y, Catalan M, Ishihara T (2009) A new global marine magnetic anomaly data set. J Geophys Res 114:B04106. https://doi.org/10.1029/2008J B006144

Sabaka TJ, Olsen N, Purucker ME (2004) Extending comprehensive models of the Earth's magnetic field with Ørsted and CHAMP data. Geophys J Int 159:521-547

Sabaka TJ, Olsen N, Tyler RH, Kuvshinov A (2015) CM5, a pre-Swarm comprehensive geomagnetic field model derived from over 12 year of CHAMP, Orsted, SAC-C and observatory data. Geophys J Int 200:1596-1626. https //doi.org/10.1093/gji/ggu493

Saturnino D, Langlais B, Civet F, Thébault E, Mandea M (2015) Main field and secular variation candidate models for the 12th IGRF generation after 10 months of Swarm measurements. Earth Planets Space 67(1):96. https //doi.org/10.1186/s40623-015-0262-7

Shom (2007) Acquisition et traitement des mesures magnétiques marines. Procédure spécifique PS2007-072. Shom's internal document

Thébault E, Purucker M, Whaler KA, Langlais B, Sabaka TJ (2010) The magnetic field of the Earth's lithosphere. Space Sci Rev 155:95-127

Thébault E et al (2015a) International Geomagnetic Reference Field: the 12th generation. Earth Planets Space 67:79. https://doi.org/10.1186/s4062 3-015-0228-9

Thébault E, Finlay CC, Alken P, Beggan CD, Canet E, Chulliat A, Langlais B, Lesur V, Lowes FJ, Manoj C, Rother M, Schachtschneider R (2015b) Evaluation of candidate geomagnetic field models for IGRF-12. Earth Planets Space 67:112. https://doi.org/10.1186/s40623-015-0273-4

Vigneron P, Hulot G, Olsen N, Léger J-M, Jager T, Brocco L, Sirol O, Coïsson P, Lalanne X, Chulliat A, Bertrand F, Boness A, Fratter I (2015) A 2015 International Geomagnetic Reference Field (IGRF) candidate model based on Swarm's experimental absolute magnetometer vector mode data. Earth Planets Space 67:95. https://doi.org/10.1186/s40623-015-0265-4

\section{Submit your manuscript to a SpringerOpen ${ }^{\odot}$ journal and benefit from:}

- Convenient online submission

- Rigorous peer review

- Open access: articles freely available online

- High visibility within the field

- Retaining the copyright to your article

Submit your next manuscript at $\boldsymbol{\nabla}$ springeropen.com 